\title{
Interannual Climate Variability in Tabuk, Saudi Arabia: Impacts on Annual and Seasonal Precipitation
}

\author{
Ali Alsubeai, Suzette R. Burckhard \\ Department of Civil \& Environmental Engineering, South Dakota State University, Brookings, SD, USA \\ Email: alialsubaie98@gmail.com, Suzette.Burckhard@sdstate.edu
}

How to cite this paper: Alsubeai, A. and Burckhard, S.R. (2021) Interannual Climate Variability in Tabuk, Saudi Arabia: Impacts on Annual and Seasonal Precipitation. Atmospheric and Climate Sciences, 11, 645-657. https://doi.org/10.4236/acs.2021.114038

Received: July 14, 2021

Accepted: August 24, 2021

Published: August 27, 2021

Copyright $\odot 2021$ by author(s) and Scientific Research Publishing Inc. This work is licensed under the Creative Commons Attribution International License (CC BY 4.0).

http://creativecommons.org/licenses/by/4.0/

\begin{abstract}
This study evaluated the annual rainfall for the Tabuk region obtained from observed datasets for the period 1978-2013. The objective of this study was to determine Tabuk catchment climate characteristics in terms of precipitation. The annual average precipitation in the Tabuk region is $33.5 \mathrm{~mm}$ which is below the global average precipitation receiving in arid regions set as less than $250 \mathrm{~mm}$. There is a drop in the annual rainfall from (25 - 30) $\mathrm{mm}$ to $(5-10)$ $\mathrm{mm}$ (1978-2004). The lowest annual rainfall $(0-6.0 \mathrm{~mm})$ occurred in the year 2004 , which is the driest year in a 35 -year period.
\end{abstract}

\section{Keywords}

Climate Variability, Arid Region, Rainfall, Temperature, Saudi Arabia

\section{Introduction}

In addition to facing water resource shortages on both ground and surface water, the Kingdom of Saudi Arabia faces the issue of flash flooding almost every year. One of the main aspects of maintaining the water sector in the kingdom is excess water management. Tabuk, like many other cities in Saudi Arabia, suffers from flash floods as it belongs to an arid climate, which is exacerbated by surface water scarcity.

With its associated high demand for agricultural water, unexpected floods and strong population growth would increase the pressure on water supplies, in Tabuk, on groundwater. Water supplies are limited, however, a comprehensive understanding of potential flooding scenarios in Tabuk is a key to the sustainable future management of water resources. Furthermore, a method for spatially dis- 
tributed surface flow estimation for the Tabuk region is still lacking.

Actions to minimize flood risk in the Kingdom of Saudi Arabia, especially in urbanized cities such as Tabuk, require accurate predictions. In addition, accurate flash flood forecasts are crucial to surface water harvesting, which is a promising, although the difficult approach to sustainable management of water supplies in the Kingdom of Saudi Arabia.

Accurate flash flood predictions in the Tabuk area are challenging for several reasons, such as, recorded rainfall data and topographic information, which are inputs to flood prediction models, are often not available in the required spatial-temporal resolution due to a sparse observation network. Spare and unknown precipitation knowledge greatly decreases the predictive efficiency of flood prediction models.

The present-day climate of the desert and semi-desert areas is known to have changed on various temporal (interannual, interdecadal multidecadal and intersessional) and spatial scales (particularly for rainfall), which represents a major challenge for the climate forecasting and modelling of these climatic variables in these areas [1].

In Saudi Arabia, some areas receive their total annual rainfall in only a few days, from intense bursts of rain over a short duration such as 3 to $5 \mathrm{hr}$. in a day. In addition, Tabuk area, Saudi Arabia has heterogeneous hydrological characteristics that are different from those of humid and even other arid areas, particularly in terms of topography, rainfall, and flash flood patterns. The objective of this paper is to present Tabuk catchment climate which has common aridity characteristics in terms of the small precipitation magnitudes and temperature rate that have been analyzed annually and monthly over 35-year period.

\section{Study Area}

1) Geography and Location

The Tabuk region is located in the extreme northwest of Saudi Arabia, with Jordan bordering on the north and the Gulf of Aqaba and the Red Sea bordering on the west (Figure 1). Surrounding it are three other administrative regions; $\mathrm{Al}$ Jouf, Hael, and Madinah. Evidently, the strategic position of the region is one of the most significant elements of economic growth due to its long sea front in the Red Sea.

In addition, being a border area allows a large proportion of trade access to Egypt, Jordan, Syria, Lebanon, and Turkey, as well as the movement of passengers and pilgrims from those countries and other countries in North Africa. The area of the Tabuk Region is 139,000 square kilometers or about $6.2 \%$ of the total area of the Kingdom. The Tabuk Region stretches from North to South covering over 580 kilometers and extends over 480 kilometers from East to West [2].

2) Climate and Topography

In the case of both the Tabuk Region and the city of Tabuk different drivers of environmental degradation have been identified. On the one hand, unsustainable 


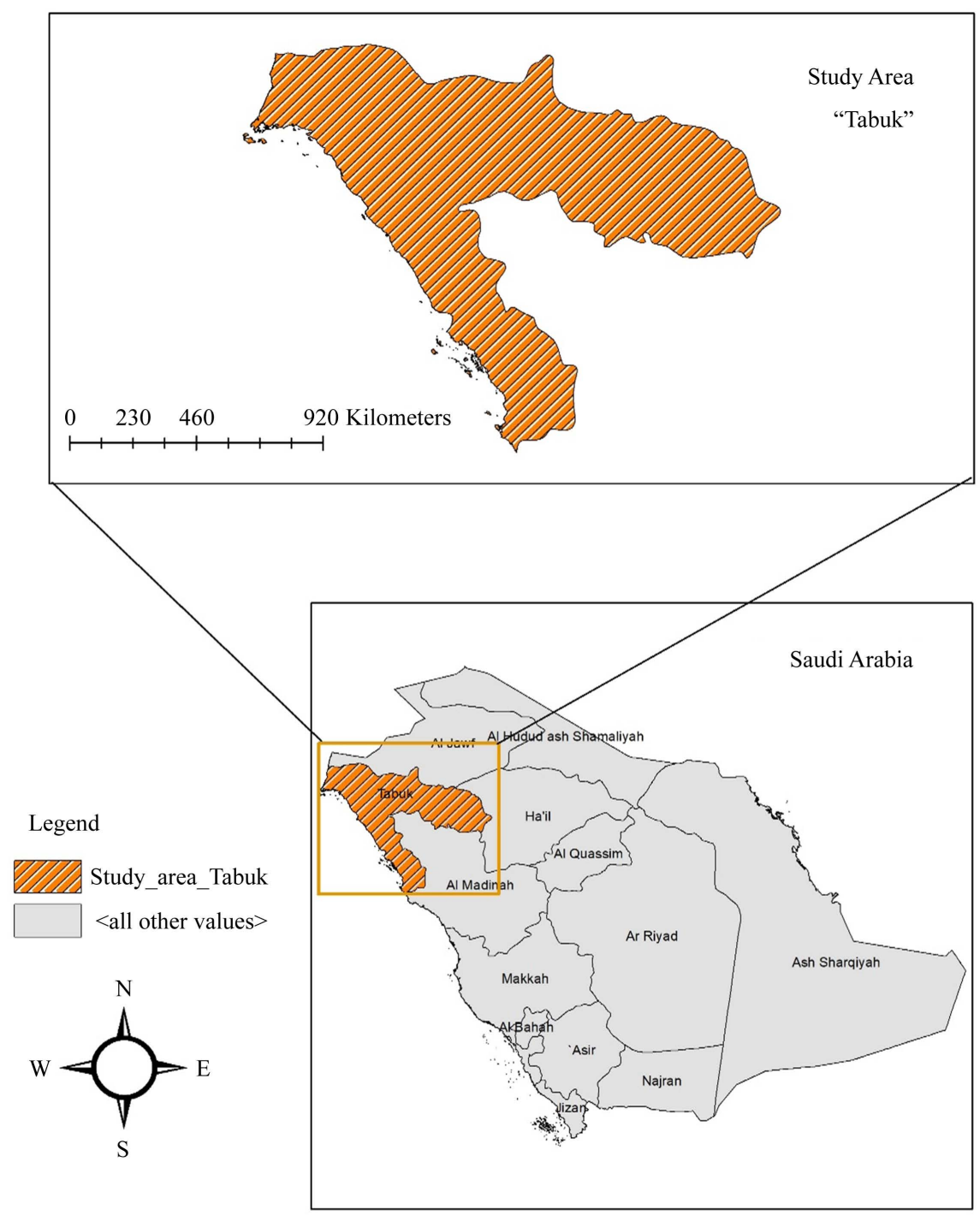

Figure 1. Tabuk geography region.

growth patterns and inadequate infrastructure are challenging future economic development and compromising existing natural resources. On the other hand, the burden on the environment is exacerbated by climate change, which is currently driving the already severe climate to more extreme conditions [2].

3) Precipitation

The dominant contribution to the low annual average rainfall in arid regions is short, high intensity rainstorms. Rainfall in the Tabuk region (Figure 2) appears to differ considerably from year to year, with an erratic distribution in time and space.

As an illustrative example of the extreme yearly variability, Tabuk rain gauge measured the annual rainfall to be $6.8,13.70,21.90,13.00,39.60,51.10$, and $13.50 \mathrm{~mm}$ over seven years. On one single day, $76.60 \mathrm{~mm}$ of rainfall occurred, even though the total annual rainfall in the same year was $92.20 \mathrm{~mm}$ observed data from Tabuk rain gauge. These types of rainfall events can lead to substantial 


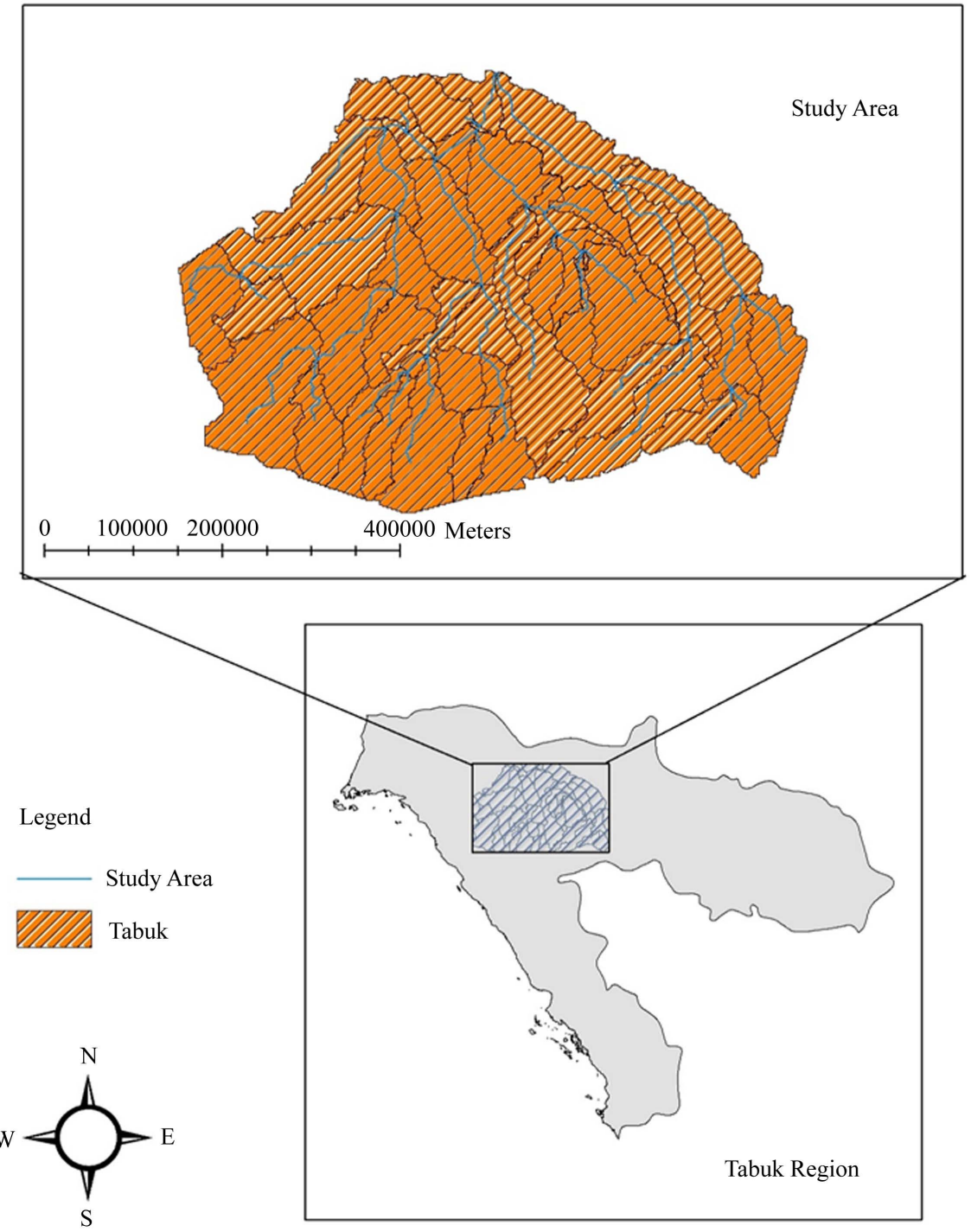

Figure 2. Tabuk watershed area and stream flows.

surface runoff, resulting in severe soil erosion. Weather behavior and topographical characteristics play important roles in this variation. Around $70 \%$ of the total annual rainfall occurs during November, December, January, February, and March.

4) Temperature

The entire Tabuk region investigated here currently has one climatic station. Tabuk station, that has complete climatic data, is located in Tabuk City. Tabuk climate is characterized by warm and dry summers (May to September) with mean degree $25.54^{\circ} \mathrm{C}, 32.43^{\circ} \mathrm{C}, 34.48^{\circ} \mathrm{C}, 34.67^{\circ} \mathrm{C}$, and $31.26^{\circ} \mathrm{C}$ respectively, whereas the temperature degrees tend to be more moderate during winters (October to April) (Table 1). The average annual temperature is $23.52^{\circ} \mathrm{C}(1999-2018)$.

5) Surface runoff

Tabuk catchment is exemplified by ephemeral wadis, where a stream runs fully for a short period of time, usually during and after heavy rain events, and is 
Table 1. Temperature description for the period of 1999-2018 (Tabuk Meteorological Station).

\begin{tabular}{ccccccc}
\hline Month & Jan & Feb & Mar & Apr & May & Jun \\
\hline Average ${ }^{\circ} \mathrm{C}$ & 10.59 & 13.40 & 17.96 & 23.66 & 28.54 & 32.43 \\
Month & Jul & Aug & Sep & Oct & Nov & Dec \\
Average ${ }^{\circ} \mathrm{C}$ & 34.48 & 34.67 & 31.26 & 25.64 & 17.31 & 12.25 \\
\hline
\end{tabular}

dry most of the year. Flash floods events fill desert dams and may recharge groundwater resources. The complex relationship between rainfall and streamflow is influenced by many factors, such as catchment slope, land cover type and density, soil type and infiltration rate, and evapotranspiration. Moreover, the quality and quantity of streamflow are strongly affected by urbanization and agricultural activity [3].

\section{Methods}

Define precipitation data between the years 1978 and 2013 at daily time intervals have been gathered, including historical and real-time observations. In addition, daily data for the selected years were available. Detection and filtering of abnormal and missing data were automated using statistical routines. The data set includes annual and monthly precipitations were provided by Tabuk meteorological station. However, the application of any climate model requires a validation process to make sure that the results are in an acceptable range.

\subsection{Statistical Analysis}

Statistics are used to display and analyze the remote sensing data. The remote sensing data of this study consist of the Tabuk watershed for 1978 and 2013. The objective of using these statistics in this research is to provide the descriptive analyses to identify the general magnitude of all observations in a data set. The mean or average was the statistical measure used in this study. In addition, the standard deviation measures the degree to which data are concentrated around the mean. A small standard deviation means that the values in a statistical dataset are close to the mean of that dataset, on average. The standard deviation ( $\sigma$ ) of a data set is the square root of its variance.

$$
\sigma=\sqrt{\frac{1}{n} \sum_{i=1}^{1}\left(x_{i}-\mu\right)^{2}}
$$

The standard deviation, also an important measurement, can be used to measure how closely the values of a data set are near the mean. In addition, the minimum, maximum, and range are a group of measurements that help in describing the data set [4].

\subsection{Climate Classification}

In this study, climate classification divides climates into three main climate groups, 
with each group being divided based on annual precipitation. The three main groups are wet, average, and dry. The mean and standard deviation are two statistical tools involved in cataloging climate. The parameters listing below (Table 2) demonstrating how data is shifting from its mean which creates the three groups of climate classification.

\section{Results and Discussion}

This study evaluated the annual rainfall for the Tabuk region obtained from observed datasets for the period 1978-2013. Over the region (1978-2004), there is a drop in the annual rainfall for the observed datasets, from approximately 25 - 30 $\mathrm{mm}$ to approximately $5-10 \mathrm{~mm}$ (Figure 3 ). The lowest annual rainfall (0 - 6.0 $\mathrm{mm}$ ) occurs over the Tabuk region in the year 2004, which is mainly the driest year in 35 -year period. Across the region, the mean annual rainfall is less than $33.5 \mathrm{~mm}$, thus classifying the climatic conditions of the Tabuk region.

However, rainfall in the year 2013 of the region ranges from $90-100 \mathrm{~mm}$ which is the highest recorded in the dataset. These results for annual rainfall in the Tabuk region are consistent with the available reported information. Table 3 displays the annual rainfall climatology over the Tabuk region for the period 19782013; this period is chosen due to the high-quality observed rainfall data being available.

Similarly, the period 1978-2013 discussed earlier, the data set period (year) is divided into three main groups as wet, average, and dry based on annual rainfall occurs periodically over the Tabuk region. The dry years (1978, 1981, 1983, 1990, $1995,1998,2002,2003,2004,2008,2011)$ and wet years $(1979,1982,1985,1986$,

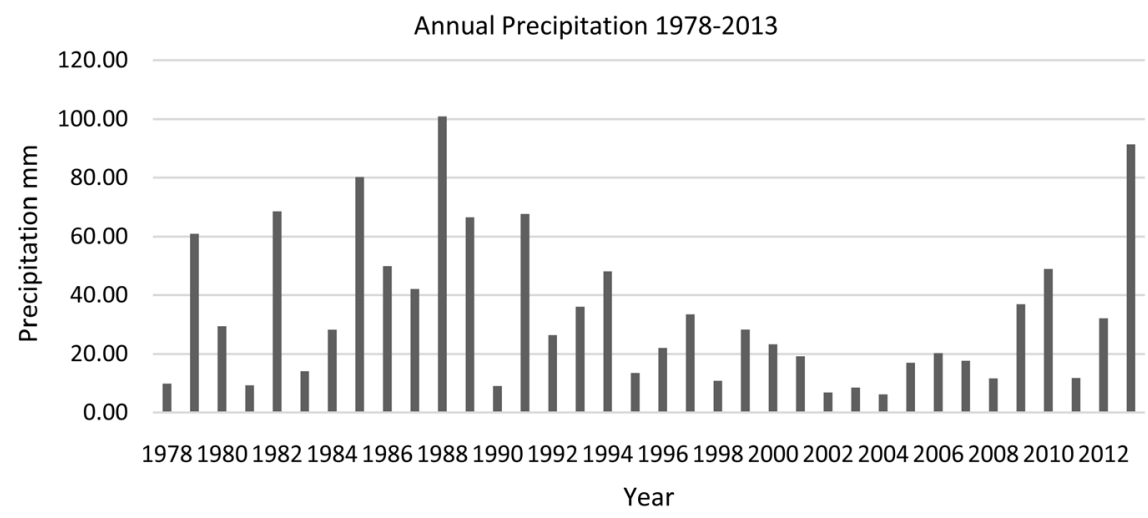

Figure 3. Annual precipitation data for Tabuk region over 35 year.

Table 2. Boundaries for climate classification based on precipitation [5].

\begin{tabular}{ccc}
\hline & Parameter & Classification \\
\hline Above & Average $+0.5 \times$ Standard Deviation & Wet \\
Between & $\begin{array}{c}\text { Average }+0.5 \times \text { Standard Deviation } \& \\
\text { Average }-0.5 \times \text { Standard Deviation }\end{array}$ & Average \\
Below & Average $-0.5 \times$ Standard Deviation & Dry \\
\hline
\end{tabular}


Table 3. Wet, average, dry, climate classification.

\begin{tabular}{lcl}
\hline & Climate Classification (Years) & \\
\hline Wet & Average & Dry \\
\hline 1979 & 1980 & 1978 \\
1982 & 1984 & 1981 \\
1985 & 1992 & 1983 \\
1986 & 1993 & 1990 \\
1987 & 1996 & 1995 \\
1988 & 1997 & 1998 \\
1989 & 1999 & 2002 \\
1991 & 2000 & 2003 \\
1994 & 2001 & 2004 \\
2010 & 2005 & 2008 \\
2013 & 2006 & 2011 \\
& 2007 & \\
& 2009 & \\
& 2012 & \\
\hline
\end{tabular}

$1987,1988,1989,1991,1994,2010,2013)$ representing the first degree of shifting the data from its mean. Thus, the results produced by the observed rainfall patterns over Tabuk region encourage the use of these datasets for studying the rainfall characteristics of the region. The average rainfall for Tabuk over different time scales is obtained from the observational datasets.

1) Annual Analysis

The plot in Figure 3 presents the annual rainfall of the Tabuk, Saudi Arabia from 1978 to 2013. Note that the total rainfall in the figure is observed data from Tabuk metrological gauge.

The results indicate that the year with the highest annual rainfall was 1988, with a total annual rainfall of $100.90 \mathrm{~mm}$. whereas, 2004 had the lowest total annual rainfall of $6.20 \mathrm{~mm}$. The average annual rainfall was $33.54 \mathrm{~mm}$ and standard deviation was 25.33. Any year with average annual rainfall higher that the average plus a half times the standard deviation is a wet year. Years with average annual rainfall that falls between the average plus half the standard deviation and the average minus half the standard deviation are considered average years. Years with average annual rainfall that fall between the average minus half the standard deviation are dry years. Table 3 shows the years sorted into the climate classifications and Table 4 shows the cut-off values used in the analysis.

2) Monthly Analysis

From the information gained in the annual analysis of annual rainfall, the monthly analysis (Figure 4) could then be conducted. The main information needed from the annual analysis was the climate classification of wet, average, 


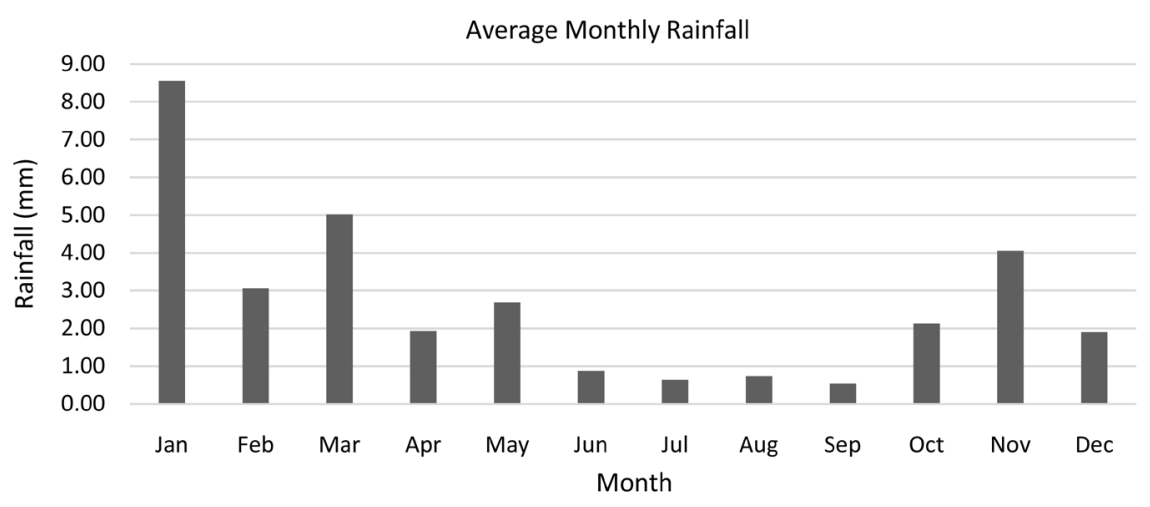

Figure 4. Monthly Rainfall Record for Tabuk 1978-2013.

Table 4. Cutoff values for the climate classification of annual precipitation (1978-2013).

\begin{tabular}{ccc}
\hline \multicolumn{3}{c}{ Analysis of Annual Rainfall of the Tabuk (1978-2013) } \\
\hline Parameter & Log Transformed (mm) & Non-Log Transformed (mm) \\
\hline Average - 1/2 STDEV & 1.27 & 20.83 \\
Average & 1.41 & 32.11 \\
Average + 1/2 STDEV & 1.56 & 43.38 \\
\hline
\end{tabular}

dry for each year (Table 3). Each year was normally distributed into 12 months a year. Month of the year in order from January to December were presented in the graphs. The years were separated into 3 different tables depending on their climate classification (wet, average, dry) and then the average and total rainfall for each month was found, along with the standard deviation for each group (Tables 5-7).

Table 5 presents that January had the highest average rainfall for wet years with an average rainfall value of $17.22 \mathrm{~mm}$. The highest monthly rainfall value for January was $75.60 \mathrm{~mm}$ in 2013 and it approximate represents $65.0 \%$ of the total rainfall occurred in January during the wet years. The lowest January monthly rainfall occurred in 1987 and it was zero. The month with the lowest average annual rainfall for wet years was July with an average rainfall value of Zero. In wet years, there is one dominating rain season (Oct-Jan) with total rain of $529.70 \mathrm{~mm}$ which is $73 \%$ from the total rain $725.30 \mathrm{~mm}$ while the total rain in period of (Feb-May) is set to be 192.30 which is only $26 \%$.

However, in Table 6, Jan had the highest average rainfall for the average years with an average rainfall value of $3.86 \mathrm{~mm}$. The highest monthly rainfall value for the Jan was $21.10 \mathrm{~mm}$ and it approximate represents 39\% during the average years. The lowest Jan rainfall occurred in 2006 and 2009, these years having an average rainfall of zero. The month with the lowest average rainfall for average years was the Sep with an average rainfall value of $0.09 \mathrm{~mm}$. 1996 had the highest Sep rainfall with a value of $1.00 \mathrm{~mm}$.

January had the highest average rainfall in dry years with an average rainfall value of $2.51 \mathrm{~mm}$ (Table 7). The highest monthly rainfall value for the January 
Table 5. Total, average, standard deviation and coefficient of variance for each year classified as wet year.

\begin{tabular}{|c|c|c|c|c|c|c|c|c|c|c|c|c|}
\hline \multicolumn{13}{|c|}{ Wet Years } \\
\hline \multicolumn{13}{|c|}{ Rainfall mm } \\
\hline Year & Jan & Feb & Mar & Apr & May & Jun & Jul & Aug & Sep & Oct & Nov & Dec \\
\hline 1979 & 0.10 & 24.60 & 0.10 & 0.10 & 13.60 & 0.10 & 0.00 & 0.00 & 0.00 & 17.50 & 0.30 & 4.50 \\
\hline 1982 & 2.00 & 2.10 & 0.50 & 25.60 & 20.90 & 0.00 & 0.00 & 0.00 & 1.00 & 1.00 & 15.50 & 0.00 \\
\hline 1985 & 0.30 & 1.50 & 3.10 & 4.30 & 0.60 & 0.00 & 0.00 & 0.00 & 0.00 & 0.10 & 10.90 & 59.40 \\
\hline 1986 & 0.70 & 0.00 & 18.50 & 12.70 & 0.00 & 0.00 & 0.00 & 0.00 & 0.00 & 1.00 & 17.00 & 0.00 \\
\hline 1987 & 0.00 & 0.50 & 0.40 & 0.00 & 0.20 & 0.00 & 0.00 & 0.30 & 0.00 & 26.30 & 0.00 & 14.40 \\
\hline 1988 & 9.50 & 0.20 & 1.10 & 13.00 & 2.20 & 0.00 & 0.00 & 0.00 & 0.00 & 52.70 & 0.00 & 22.20 \\
\hline 1989 & 21.00 & 0.00 & 6.00 & 1.50 & 0.50 & 0.00 & 0.00 & 0.00 & 0.00 & 0.00 & 19.50 & 18.10 \\
\hline 1991 & 36.20 & 0.20 & 24.20 & 0.00 & 0.00 & 0.00 & 0.00 & 0.00 & 0.00 & 6.00 & 0.00 & 1.10 \\
\hline 1994 & 5.20 & 0.60 & 0.00 & 0.20 & 1.50 & 0.00 & 0.00 & 0.00 & 1.90 & 25.00 & 13.40 & 0.30 \\
\hline 2010 & 38.80 & 0.00 & 0.70 & 0.10 & 5.00 & 0.00 & 0.00 & 0.00 & 0.00 & 0.00 & 0.00 & 4.30 \\
\hline 2013 & 75.60 & 5.50 & 0.00 & 0.00 & 0.50 & 0.00 & 0.00 & 0.00 & 0.10 & 0.00 & 0.00 & 9.80 \\
\hline Total & 189.40 & 35.20 & 54.60 & 57.50 & 45.00 & 0.10 & 0.00 & 0.30 & 3.00 & 129.60 & 76.60 & 134.10 \\
\hline Mean & 17.22 & 3.20 & 4.96 & 5.23 & 4.09 & 0.01 & 0.00 & 0.03 & 0.27 & 11.78 & 6.96 & 12.19 \\
\hline Stdev & 24.15 & 7.28 & 8.39 & 8.40 & 6.86 & 0.03 & 0.00 & 0.09 & 0.62 & 17.06 & 8.21 & 17.49 \\
\hline $\mathrm{CV}$ & 1.40 & 2.28 & 1.69 & 1.61 & 1.68 & 3.32 & 0.00 & 3.32 & 2.26 & 1.45 & 1.18 & 1.43 \\
\hline Max & 75.60 & 24.60 & 24.20 & 25.60 & 20.90 & 0.10 & 0.00 & 0.30 & 1.90 & 52.70 & 19.50 & 59.40 \\
\hline
\end{tabular}

Table 6. Total, average, and standard deviation and coefficient of variance for each year classified as average year.

\begin{tabular}{|c|c|c|c|c|c|c|c|c|c|c|c|c|}
\hline \multicolumn{13}{|c|}{ Average Years } \\
\hline \multicolumn{13}{|c|}{ Rainfall mm } \\
\hline Year & Jan & Feb & Mar & Apr & May & Jun & Jul & Aug & Sep & Oct & Nov & Dec \\
\hline 1980 & 0.80 & 13.80 & 0.80 & 0.10 & 0.50 & 0.00 & 0.00 & 0.00 & 0.10 & 4.10 & 2.20 & 7.10 \\
\hline 1984 & 0.10 & 0.10 & 2.60 & 0.00 & 0.00 & 0.00 & 0.00 & 0.00 & 0.00 & 18.70 & 6.80 & 0.00 \\
\hline 1992 & 2.00 & 1.40 & 0.00 & 0.00 & 0.00 & 0.00 & 0.00 & 20.00 & 0.00 & 0.00 & 2.40 & 0.70 \\
\hline 1993 & 1.40 & 1.40 & 0.30 & 4.80 & 0.90 & 0.00 & 0.00 & 0.00 & 0.00 & 9.50 & 0.00 & 17.70 \\
\hline 1996 & 0.70 & 0.00 & 1.40 & 0.10 & 0.00 & 0.00 & 1.60 & 1.00 & 1.00 & 0.00 & 12.10 & 4.20 \\
\hline 1997 & 21.10 & 0.10 & 2.50 & 0.00 & 2.80 & 0.00 & 0.00 & 0.00 & 0.00 & 6.60 & 0.00 & 0.30 \\
\hline 1999 & 2.60 & 14.00 & 11.40 & 0.00 & 0.20 & 0.00 & 0.00 & 0.00 & 0.00 & 0.00 & 0.00 & 0.20 \\
\hline 2000 & 7.60 & 2.50 & 0.00 & 0.00 & 0.20 & 0.00 & 0.20 & 0.00 & 0.00 & 1.10 & 7.70 & 4.00 \\
\hline 2001 & 2.30 & 0.20 & 1.90 & 12.60 & 1.80 & 0.00 & 0.00 & 0.00 & 0.00 & 0.00 & 0.00 & 0.40 \\
\hline 2005 & 7.90 & 2.00 & 4.10 & 1.00 & 2.00 & 0.00 & 0.00 & 0.00 & 0.00 & 0.00 & 0.00 & 0.00 \\
\hline 2006 & 0.00 & 6.00 & 8.40 & 0.00 & 5.70 & 0.00 & 0.00 & 0.00 & 0.00 & 0.10 & 0.10 & 0.00 \\
\hline 2007 & 7.50 & 2.30 & 3.00 & 1.20 & 2.40 & 0.00 & 0.00 & 0.00 & 0.00 & 1.30 & 0.00 & 0.00 \\
\hline
\end{tabular}




\section{Continued}

\begin{tabular}{ccccccccccccccc}
\hline 2009 & 0.00 & 1.30 & 0.00 & 0.00 & 23.50 & 8.00 & 0.00 & 0.00 & 0.00 & 0.00 & 4.10 & 0.00 \\
2012 & 0.10 & 5.30 & 0.10 & 8.50 & 0.00 & 0.00 & 0.00 & 0.00 & 0.10 & 16.80 & 1.10 & 0.00 \\
Total & 54.10 & 50.40 & 36.50 & 28.30 & 40.00 & 8.00 & 1.80 & 21.00 & 1.20 & 58.20 & 36.50 & 34.60 \\
Mean & 3.86 & 3.60 & 2.61 & 2.02 & 2.86 & 0.57 & 0.13 & 1.50 & 0.09 & 4.16 & 2.61 & 2.47 \\
STDEV & 5.76 & 4.73 & 3.40 & 3.92 & 6.15 & 2.14 & 0.43 & 5.33 & 0.27 & 6.47 & 3.78 & 4.90 \\
CV & 1.49 & 1.31 & 1.31 & 1.94 & 2.15 & 3.74 & 3.32 & 3.55 & 3.10 & 1.56 & 1.45 & 1.98 \\
Max & 21.10 & 14.00 & 11.40 & 12.60 & 23.50 & 8.00 & 1.60 & 20.00 & 1.00 & 18.70 & 12.10 & 17.70 \\
\hline
\end{tabular}

Table 7. Total, average, standard deviation and coefficient of variance for each year classified as dry year.

\begin{tabular}{|c|c|c|c|c|c|c|c|c|c|c|c|c|}
\hline \multicolumn{13}{|c|}{ Dry Years } \\
\hline \multicolumn{13}{|c|}{ Rainfall mm } \\
\hline Year & Jan & Feb & Mar & Apr & May & Jun & Jul & Aug & Sep & Oct & Nov & Dec \\
\hline 1978 & 0.00 & 1.40 & 0.00 & 0.00 & 0.00 & 0.00 & 0.00 & 0.00 & 0.00 & 0.10 & 0.00 & 8.40 \\
\hline 1981 & 0.00 & 1.00 & 2.20 & 0.60 & 2.00 & 0.00 & 1.00 & 2.20 & 0.00 & 0.30 & 0.00 & 0.00 \\
\hline 1983 & 2.00 & 3.00 & 1.90 & 0.00 & 3.60 & 1.00 & 0.00 & 0.10 & 0.00 & 0.00 & 0.00 & 2.50 \\
\hline 1990 & 2.00 & 0.00 & 0.00 & 2.00 & 0.00 & 0.00 & 0.00 & 0.00 & 0.00 & 3.20 & 0.00 & 1.90 \\
\hline 1995 & 0.20 & 0.40 & 10.90 & 0.20 & 1.00 & 0.00 & 0.00 & 0.00 & 0.10 & 0.10 & 0.20 & 0.40 \\
\hline 1998 & 3.40 & 1.60 & 3.20 & 0.20 & 2.20 & 0.00 & 0.00 & 0.10 & 0.00 & 0.00 & 0.10 & 0.00 \\
\hline 2002 & 1.70 & 1.00 & 0.00 & 0.00 & 0.00 & 0.00 & 0.00 & 0.00 & 0.00 & 1.50 & 2.60 & 0.00 \\
\hline 2003 & 1.00 & 0.00 & 0.00 & 0.00 & 3.00 & 0.00 & 0.00 & 3.00 & 0.00 & 0.10 & 0.00 & 1.20 \\
\hline 2004 & 5.00 & 0.60 & 0.00 & 0.00 & 0.00 & 0.00 & 0.00 & 0.00 & 0.00 & 0.40 & 0.10 & 0.10 \\
\hline 2008 & 8.50 & 1.00 & 0.20 & 0.00 & 0.00 & 0.00 & 0.00 & 0.00 & 0.00 & 0.00 & 1.50 & 0.50 \\
\hline 2011 & 3.80 & 3.20 & 0.20 & 4.60 & 0.00 & 0.00 & 0.00 & 0.00 & 0.00 & 0.00 & 0.00 & 0.00 \\
\hline Total & 27.60 & 13.20 & 18.60 & 7.60 & 11.80 & 1.00 & 1.00 & 5.40 & 0.10 & 5.70 & 4.50 & 15.00 \\
\hline Mean & 2.51 & 1.20 & 1.69 & 0.69 & 1.07 & 0.09 & 0.09 & 0.49 & 0.01 & 0.52 & 0.41 & 1.36 \\
\hline STDEV & 2.57 & 1.07 & 3.26 & 1.43 & 1.38 & 0.30 & 0.30 & 1.06 & 0.03 & 0.99 & 0.85 & 2.49 \\
\hline $\mathrm{CV}$ & 1.02 & 0.89 & 1.93 & 2.06 & 1.29 & 3.32 & 3.32 & 2.16 & 3.32 & 1.91 & 2.08 & 1.82 \\
\hline Max & 8.50 & 3.20 & 10.90 & 4.60 & 3.60 & 1.00 & 1.00 & 3.00 & 0.10 & 3.20 & 2.60 & 8.40 \\
\hline
\end{tabular}

was 8.50 and it represents $30 \%$ of the total rainfall during the dry years. The lowest January rainfall occurred in 1978 and 1981 having a rainfall value of zero. In addition, Sep was the month with the lowest average rainfall for dry years with an average rainfall value of $0.01 \mathrm{~mm} .1995$ had the highest Sep rainfall with a value of $0.10 \mathrm{~mm}$. The lowest rainfall value was with a rainfall value of zero. In dry years, there are two equal rain seasons with $52.80 \mathrm{~mm}$ (Oct-Jan) and 51.20 $\mathrm{mm}$ (Feb-May). These two seasons equally represent $50 \%$ of the total rainfall during dry years.

Tabuk climate behavior has wide ringed in both space and time, thus causing 
and affecting the precipitation magnitudes. For this reason, Tabuk arid catchments are more open to simplified models.

The results have wide-ranging practical and scientific significance. First of all, they provide a modelling framework for a regional climate classification in the Tabuk Region, based on a detailed observed data presented monthly and annually. The modelling framework may assist future water resource management, which will face increasing water scarcity in the study region. In addition, this study successfully tested the existing applicability of climate and precipitation models in arid regions, which are usually not in the focus of hydrological model development [6].

To explore the links between climate and rainfall intensity in Tabuk region, this study analyzed 35-year of detailed rainfall data monthly measured from a meteorological station. In Tabuk catchment, most rainfall events are based on one or two incidents which contain high percentage of the total rainfall recorded. Those short and intense events are mainly the reason of flash flooding besides lacking vegetation cover and poor infrastructure facilities.

The total annual rainfall showed an increase above the normal occurring once in four or five years. Also, total annual rainfall is an excellent indicator of whether the year experienced an acute rainfall deficiency (less than $60 \mathrm{~mm}$ ). For the past four decades rainfall has been recorded in the study area (Figure 3). Rainfall was considered as the main factor in dealing with understanding whether the study area has suffered an above or below normal receipt of atmospheric moisture.

Initially, climatic analysis of rainfall showed that the study area has climatic characteristics of an extreme arid environment. Nevertheless, the study area has the advantage of rainfall occurring in the winter season, which increases moisture effectiveness and the availability of existing vegetation to maximize the lifesupporting impact of small amounts of water. However, the summer season receives little rainfall comparing to winter season.

The Tabuk area has the typical arid environment, characterized by low rainfall that may cause temporary and long-term deterioration in the natural landscape. Rainfall, prior to the 1988 was much higher or above normal, compared to the last twenty years of data set, which means that the wet condition was dominating in that period. On the other hand, the rainfall data for the period between 1990 and 2010 indicates that the Tabuk area has been subjected to limited rainfall.

The preliminary analysis of rainfall data revealed that the annual average rainfall in the region varies from $6 \mathrm{~mm}$ /year to $100 \mathrm{~mm}$ /year, with a weighted average rainfall of $33.54 \mathrm{~mm} /$ year for the entire command area. A total of $60 \%$ of total annual rainfall occurs in the wet years.

Most of wet years were placed in the first 20 -year of the data set. This divided data into two subjected pattern which represents a series of wet years occurrence with total annual precipitation above the average. As expected, we found that statistically defined wet years have occurred more frequently in much earlier decades relative to recent decades. With this pattern evident nine years of the 
total wet years occurred in (1979-1994). No such decadal patterns were evident in the occurrence of extreme dry years. Furthermore, when each climate classification was analyzed separately, differences among years in these precipitation regimes also were significant. When comparing wet vs. dry years, the total amount of precipitation that was most important for distinguishing these two types of years.

The variability of annual and seasonal rainfall and rainy days was evaluated using the CV. The Coefficient of Variation indicated the relative variability of annual rainfall is higher for 1978, 1984, 1985, 1987, 1992, 1995, 2004, 2008, 2010, and 2013 and these years have showed great variability in rainfall for all months. The CV for weighted mean seasonal rainfall of the command area is approximately 2.04. A data series with smaller variation will have lower $\mathrm{CV}$, and the numerical value of the CV depends on the value range of the data series. Ideally annual rainfall or seasonal rainfall should not show any variation; however, the annual or seasonal rainfall does exhibit variation.

In wet years, there are high variations in June and August (3.32), whereas January and November calculated as 1.40 and 1.18 respectively which are the lowest. This shows that there is high variation during summer season which may be due to some intense rainstorms. These rainstorms are the primary cause of generating floods during summer season in wet years.

Average years have similar case to wet years when high variations occur in June and August, whereas February and March were calculated as 1.31 which is the lowest. This shows that there is high variation during summer season which may cause some intense rainstorms. These rainstorms are the primary cause of generating floods during summer season in average years.

In dry years, there are high variations in June and August (3.32) which the case in wet years, whereas January and February calculated as 1.02 and 0.89 respectively which are the lowest. This shows that there is high variation during summer season which may cause some intense rainstorms. These rainstorms are the primary cause of generating floods during summer season in wet years.

Overall, there is a significant variation in wet and dry years during summer season when there is high potential of flooding occurrence compared to average years. This sort of floods is difficult to predict and can cause severe harm to people lives and infrastructure as well. The low amount of annual precipitation due to the desert weather may lead to false estimation of flooding hazards. Rainfall events in arid regions are characterized as short-high intense which means most of water turns to generate surface flow.

This paper presents a hydrologically motivated alternative to traditional climate classification schemes, accounting for gradual changes in climate and the influence that has on flow regimes and streamflow signatures. We find that the wide range and high variation in wet years are the primary cause of generating floods during winter season while the variation in average and dry years extended to cover the summer in addition to the winter. 


\section{Conclusions}

In this paper, the climatology of monthly and annual rainfall in the Tabuk region has been analyzed using the available data from Tabuk meteorological station. The mean amount of annual rainfall seems to be homogeneous.

Analysis of these data shows that the highest amounts of rainfall occur during November in the wet years. While the highest amounts of rainfall occur during the average years in March. Dry years are the lowest annual rainfall in Tabuk when the climate is harsh and temperature degree gets to its maximum in Jun, July, and August.

\section{Acknowledgements}

The authors would like to thank the Saudi Arabian Cultural Mission (SACM) for their generous support in funding this study. Also, the authors would like to thank The Department of Civil \& Environmental Engineering at South Dakota State University for providing the GIS and remote sensing tools and packages used in this paper.

\section{Conflicts of Interest}

The authors declare no conflicts of interest regarding the publication of this paper.

\section{References}

[1] Lioubimtseva, E. (2004) Climate Change in Arid Environments: Revisiting the Past to Understand the Future. Progress in Physical Geography. Earth and Environment, 28, 502-530. https://doi.org/10.1191/0309133304pp422oa

[2] UN-Habitat. (2019). Tabuk City Profile: UN-Habitat. UN. https://unhabitat.org/tabuk-city-profile

[3] Vernon, C.M., Halpin, P.N. and Stow, C.A. (2005) Patterns of Watershed Urbanization and Impacts on Water Quality. Journal of the American Water Resources Association (JAWRA), 41, 693-708. https://doi.org/10.1111/j.1752-1688.2005.tb03764.x

[4] Yamane, T. (1967) Statistics-An Introductory Analysis. Second Edition, Harper \& Row Publisher, 1-126.

[5] Ruppert, S. (2019) Stream Flow Analysis of the Big Sioux River Just South of Brookings, South Dakota. Electronic Theses and Dissertations, South Dakota State University, Brookings, SD, 3269.

[6] Wheater, H.S., Sorooshian, S. and Sharma, K.D. (2008) Hydrological Modelling in Arid and Semi-Arid Areas. Cambridge University Press, Cambridge, 195 p. https://doi.org/10.1017/CBO9780511535734 